\title{
Notas sobre Passiflora ischnoclada Harms (Passifloraceae) ${ }^{1}$
}

\author{
Luís Carlos Bernacci
}

Recebido em 17/06/99. Aceito em 23/03/01

\begin{abstract}
RESUMO - (Notas sobre Passiflora ischnoclada Harms (Passifloraceae)). Passiflora ischnoclada foi descrita com base em apenas uma coleta. O único exemplar conhecido estava depositado no herbário de Berlin-Dahlem (B), mas foi destruído. A sinonimização da espécie em P. jilekii Wawra havia sido proposta, com base apenas em sua descrição original, mas, outro exemplar da coleção-tipo foi localizado no herbário do Instituto de Botânica (SP) e P. ischnoclada foi recoletada na mesma área, quase um século depois. Foi possível comprovar a validade da espécie e seu posicionamento na série Laurifoliae e complementar sua descrição, acrescentando caracteres das flores e do fruto imaturo.
\end{abstract}

Palavras-chave - Passifloraceae, Passiflora ischnoclada, São Paulo, Brasil.

ABSTRACT -(Notes on Passiflora ischnoclada Harms (Passifloraceae)). The description of Passiflora ischnoclada was based on the type collection. The only mentioned material was deposited in the Berlin-Dahlem herbarium (B) and was destroyed. The synonimization of $P$. ischnoclada under $P$. jilekii was proposed according to that description. Recently another material from the type collection was found in the SP herbarium and the species was collected again in the type locality. In this work the reestablishment of $P$. ischnoclada is proposed as well as the position of the species in the series Laurifoliae is discussed, and the description of the species is complemented, with adding characters of the flowers and the immature fruit.

Key words - Passifloraceae, Passiflora ischnoclada, São Paulo, Brazil.

\section{Introdução}

Passiflora ischnoclada foi descrita por Harms (1929), sem indicação do holótipo nem menção de herbários, com base na coleção A. Löfgren CGG 5754 coletada em 1901, na comarca paulista de Santa Branca, no município de Salesópolis. O material de $P$. ischnoclada apresentava apenas botões e Harms (1929) apontou semelhanças, quanto às brácteas coloridas e membranáceas e forma das folhas, com P. jilekii Wawra, da qual, entretanto, difereria pelas estípulas estreitas. Killip (1938) citou um exemplar da coleção original de $P$. ischnoclada, depositado no herbário do Museu de Berlin-Dahlem (B) e perdido no incêndio em 1943 (Zepernick 1979), considerou a espécie na série Laurifoliae e apontou suas semelhanças com $P$. popenovii Killip, da mesma série, e com $P$. jilekii e $P$. actinia Hook., da série Simplicifoliae. Cervi (1997) sinonimizou $P$. ischnoclada em $P$. jilekii, com base na morfologia das folhas e das brácteas.

\footnotetext{
${ }^{1}$ Estudo desenvolvido como parte do projeto "Flora Fanerogâmica do Estado de São Paulo", financiado pela FAPESP e CNPq ${ }^{2}$ Centro de Recursos Genéticos e Jardim Botânico, Instituto Agronômico - IAC, Cx. Postal 28, CEP 13001-970, Campinas, SP, Brasil.e-mail: bernacci@barao.iac.br
} 
Durante a elaboração da monografia de Passifloraceae da Flora Fanerogâmica do Estado de São Paulo, foram examinados um exemplar da coleção original depositado no herbário do Instituto de Botânica (SP) e materiais oriundos de coletas recentes, sendo possível confirmar a validade de $P$. ischnoclada, seu posicionamento na série Laurifoliae e complementar sua descrição, acrescentando caracteres das flores e do fruto imaturo.

\section{Material e métodos}

Foram utilizados os procedimentos usuais em trabalhos dessa natureza. A comparação entre $P$. ischnoclada e $P$. jilekii foi feita com base nos seguintes materiais selecionados desta última espécie: F.Barros 470 (SP), R.D.Cantack 11 (BOTU), A.S.Grotta s.n. (IAC33786, FUEL10244, SPF15142, UPCB19932), H.F.Leitão Filho 1500 (UEC), G.Pabst 6772 (HB), J.E.L.S.Ribeiro 235 (HRCB), R.R.Rodrigues s.n. (ESA7070).

\section{Resultados e discussão}

Passiflora ischnoclada Harms, Notizbl. Bot. Gart. Berlin 10: 812. 1929. Tipo: BRASIL. São Paulo, comarca de Santa Branca, município de Salesópolis, rio Claro, capoeirão, 20/08/1901, botões, A.Löfgren CGG 5754 (B destr); (Lectótipo SP, aqui designado).

Trepadeira lenhosa, glabra; ramos subcilíndricos. Estípulas 3-9mm, filiformes; pecíolo 0,9-1,6cm, com 1-2 pares de nectários (aquele mais próximo à lâmina, às vezes incompleto), dispersos, $1 \mathrm{~mm}$, estipitados; lâmina cartácea a coriácea ou membranácea, $(3,9) 4,9-7,4 \times 2,3-5 \mathrm{~cm}$, ovada a ovado-lanceolada ou ovado-oblonga, ápice agudo, curtamente mucronulado, base arredondada a subcordada, $1 \mathrm{~mm}$ peltada, freqüentemente discolor com a face adaxial glauco-brilhante; nervação conspícua em ambas as faces, avermelhada na face abaxial, nas folhas novas. Flor solitária, ca. $7,6 \mathrm{~cm}$ diâm., vistosa; pedicelo 5,8-10,3(11)cm compr., articulado a 3-4(6)mm compr. da base do hipanto; brácteas 3, verticiladas, 2,3$3,9 \times 1,6-3,2 \mathrm{~cm}$, ovais, ápice obtuso, mucronulado, base arredondada a cordada, violetas a róseo-escuro; hipanto 6-9x8-11 mm, campanulado; sépalas membranáceas, 3,1$3,5 \times 0,8-1,1 \mathrm{~cm}$, com arista $1-2 \mathrm{~mm}$, oblongas, face abaxial rosa-claro com nervação rosaescuro e ápice verde-amarelado; pétalas 3$3,2 \times 0,6-0,9 \mathrm{~cm}$, oblongas, rosa-claro; corona em 4 séries filiformes, a externa ereta, $5 \mathrm{~mm}$ compr., as internas deflexas, 1-2mm compr., menores para o centro, com ápice côncavotruncado; opérculo ereto, $2 \mathrm{~mm}$, membranoso na metade inferior, filamentoso na superior; 10 invaginações nectaríferas verticais, da base do hipanto até o opérculo; limem 1,5m; androginóforo 1,3-2,2cm; filete $0,8-1 \mathrm{~cm}$, antera $4-6 \mathrm{~mm}$; ovário $7-8 \times 2 \mathrm{~mm}$, glabro, ovóide; estilete 0,9-1,2cm compr. Baga $3,1 \times 2,2 \mathrm{~cm}$, ovada, odorífera, ainda imatura; semente $3 \times 2 \mathrm{~mm}$, obovada, testa lisa, ainda imatura.

Material adicional examinado: BRASIL. São Paulo: Salesópolis, I/1990, fl., fr. imat., A.Jouy B975 (SPSF); Salesópolis, XI/1994, fl., R. Simão-Bianchini 601 (IAC, SP, SPF, UEC); Salesópolis, IV/2000, fr. imat., W.Foster et al. 309 (ESA); Caraguatatuba, IV/2000, fl. J.P.Souza et al. 3505 (ESA).

Coletada com flores entre novembro e abril e com frutos imaturos entre janeiro e abril. Passiflora ischnoclada difere de $P$. jilekii por apresentar apenas uma flor por nó, pedicelo, flores e brácteas maiores, corona mais curta com as séries internas reflexas e o nectário com invaginações verticais em vez de um anel. Vegetativamente, pode ser distinta pela lâmina foliar e pecíolo menores e número menor de nectários, um a dois pares em $P$. ischnoclada e três a seis nectários (às vezes pareadas) em $P$. jilekii. Além disso, 
enquanto $P$. ischnoclada apresenta as estípulas filiformes, situando-se na série Laurifoliae Killip ex Cervi, P. jilekii as apresenta reniformes, situando-se na série Simplicifoliae (Harms) Killip. Cervi (1997) caracterizou a Série Laurifoliae pelas "folhas simples e inteiras com mais de $2,5 \mathrm{~cm}$ de largura; brácteas livres na base, maiores de $1 \mathrm{~cm}$ de comprimento, arredondadas no ápice e pecíolo com 2 glândulas". Entretanto, $P$. ischnoclada pode apresentar 2-4 glândulas no pecíolo, implicando na necessidade de pequena alteração dos caracteres diagnósticos da Série Laurifoliae. Quanto à distribuição geográfica, $P$. jilekii ocorre no litoral e na região sudeste de São Paulo e em Minas Gerais e Santa Catarina, enquanto $P$. ischnoclada é uma espécie rara, apresentando área de ocorrência bastante limitada, além de pequena abundância, fortalecendo a suposição de que a mesma está ameaçada de extinção, enquadrando-se na categoria "em perigo".

\section{Agradecimentos}

Aos colegas que efetuaram coletas recentes de $P$. ischnoclada, possibilitando conhecer melhor a espécie, a Fábio A. Vitta pelo auxílio em relação ao abstract e à assessoria (anônima) pelas críticas e valiosas sugestões.

\section{Referências bibliográficas}

CERVI, A.C. 1997. Passifloraceae do Brasil: estudo do gênero Passiflora L., subgênero Passiflora. FontQueria 45: 1-92

HARMS, H. 1929. Passifloraceae americanae novae. Notizbl. Bot. Gart. Berlin 10: 808-821

KILLIP, E.P. 1938. The American species of Passifloraceae. Botanical Series 49, Field Museum of Natural History, 613pp, Chicago.

ZEPERNICK, B. 1979. Typen der Flacourtiineae (ausgenommen Flacourtiaceae) im Generalherbar des Botanischen Museums Berlin-Dahlem.

Willdenowia 9: 199-202 